\title{
Aerosol particle concentrations with different oxygen devices and interfaces for spontaneous breathing patients with tracheostomy: a randomised crossover trial
}

\begin{abstract}
To the Editor:
Copyright @The authors 2021

This version is distributed under the terms of the Creative Commons Attribution NonCommercial Licence 4.0. For commercial reproduction rights and permissions contact permissions@ersnet.org

Received: 30 July 2021 Accepted: 20 Aug 2021
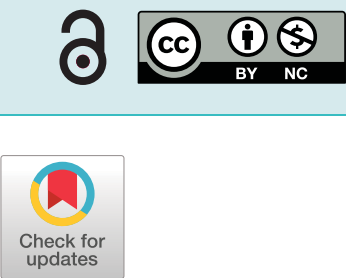

The transmission route of the severe acute respiratory syndrome coronavirus 2 (SARS-CoV-2) virus remains controversial [1, 2], and concerns persist of potentially increased virus transmission and aerosol dispersion when using high-flow oxygen and aerosol devices among coronavirus disease (COVID-2019) patients [2-5]. Spontaneous breathing patients with tracheostomy represent a more direct conduit for dispersing aerosol particles with risk of virus transmission [6]. The tracheostomy procedure is considered a high-risk aerosol generating procedure and high-level personal protection equipment (PPE) is recommended when the tracheostomy is being performed for COVID-19 patients [7]. However, aerosol dispersion transmission risk of bioaerosols via tracheostomy during spontaneous breathing has not been evaluated and the impact of different humidification devices and interfaces are unknown.

A heat-moisture exchange filter (HMEF) provides heat and humidification while filtering the exhaled gas from patients (figure 1) [6, 8], but is not suitable for patients with copious or thick secretions, and can be occluded by secretions, resulting in an increased work of breathing or complete obstruction of the inner cannula. Large volume nebulisers (LVNs) are commonly used with tracheostomy mask for patients with a tracheostomy, despite concerns that cool gas may cause airway irritation or dry secretions. A venturi adapter with tracheostomy mask is commonly utilised during transport or patient mobilisation. Lastly, heated high-flow high humidity has been shown to improve comfort and secretion management in tracheostomy patients [9-11]. The aerosol particle concentrations generated by patients via tracheostomy stoma with these devices are unknown. This study aimed to investigate the ambient aerosol particle concentrations among different oxygen and humidification devices for spontaneous breathing patients with a tracheostomy, in order to assess the transmission risk.

This prospective, randomised cross-over trial was approved by the Rush University ethics committee (approval No. 20112506-IRB01) and registered with clinicaltrials.gov (NCT04654754). Adult tracheostomy patients who were able to breathe without ventilator support were enrolled. Patients were excluded if they met any of the following criteria: had positive test for COVID-19 within the past 2 weeks; were non-English speaking or unable to communicate or make any decision; refused to participate in the study; or were receiving palliative care or extracorporeal membrane oxygenation.

After signing the consent form, patients received oxygen therapy with four devices in a random order: 1) heated high-flow high humidity device with tracheostomy adapter (Airvo2; Fisher \& Paykel healthcare, Auckland, New Zealand) operated at $30 \mathrm{~L} \cdot \mathrm{min}^{-1}$ (figure 1); 2) LVN (AirLife Prefilled Nebulizer Kit; Vyaire Medical, Mettawa, IL, USA) with tracheostomy mask (AirLife; Vyaire Medical); 3) LVN with T-piece and a bacterial/viral filter (AirLife; Vyaire Medical) [8]; and 4) Venturi-adapter with tracheostomy mask. Both the LVN and Venturi-adapter were operated at $6 \mathrm{~L} \cdot \mathrm{min}^{-1}$ and fraction of inspired oxygen $\left(F_{\mathrm{IO}_{2}}\right)$ at 0.28 . Each device was used for $5 \mathrm{~min}$. An HMEF placed at the tracheostomy tube was used prior to the study and between devices, with an interval of $10 \mathrm{~min}$. A particle counter (Model 3889; Kanomax, Andover, NJ, USA) was placed at 1 foot from patient's face to continuously measure aerosol particle concentrations in the room. During the study, the investigator wore an N95 mask and stayed in the room

\section{Shareable abstract (@ERSpublications)}

For stable spontaneously breathing tracheostomy patients with uncuffed airways, different humidification devices and interfaces did not generate clinically significant differences of aerosol particle concentrations https://bit.ly/2Y1HSO2

Cite this article as: Li J, Schoenrock C, Fink JB. Aerosol particle concentrations with different oxygen devices and interfaces for spontaneous breathing patients with tracheostomy: a randomised crossover trial. ERJ Open Res 2021; 7: 00486-2021 [DOI: 10.1183/23120541.00486-2021].
\end{abstract}




\begin{tabular}{|c|c|c|c|c|c|c|}
\hline \multirow{3}{*}{$\begin{array}{l}\text { Particle } \\
\text { size, } \mu \mathrm{m}\end{array}$} & \multicolumn{5}{|c|}{ Particle concentrations, particles per $\mathrm{m}^{3}$} & \multirow{3}{*}{ p-value } \\
\hline & & & & & & \\
\hline & Baseline with HMEF & $\begin{array}{c}\text { Airvo2 with } \\
\text { tracheostomy adapter }\end{array}$ & $\begin{array}{l}\text { LVN with a } \\
\text { tracheostomy mask }\end{array}$ & $\begin{array}{l}\text { Venturi adapter with } \\
\text { a tracheostomy mask }\end{array}$ & $\begin{array}{l}\text { LVN with T-piece } \\
\text { and a filter }\end{array}$ & \\
\hline$<0.3, \times 10^{6}$ & $13.0(7.9-25.4)$ & $10.5(7.7-23.0)$ & $15.2(7.2-26.0)$ & $12.1(6.9-26.6)$ & $11.9(7.3-25.5)$ & 0.569 \\
\hline $0.3-0.5, \times 10^{5}$ & $6.8(4.1-19.6)$ & $6.1(4.6-17.9)$ & $7.3(3.8-31.5)$ & $6.1(3.6-22.1)$ & $5.9(3.9-17.6)$ & 0.061 \\
\hline $0.5-1.0, \times 10^{4}$ & $5.0(4.2-13.9)$ & $5.3(3.5-13.7)$ & $5.5(3.6-14.0)$ & $4.6(3.6-13.2)$ & $5.2(3.6-10.1)$ & 0.663 \\
\hline $1.0-3.0, \times 10^{4}$ & $1.3(0.9-2.5)$ & $1.3(1.0-3.1)$ & $1.1(0.6-2.9)$ & $1.0(0.8-2.3)$ & $1.2(0.7-2.6)$ & 0.644 \\
\hline $3.0-5.0, \times 10^{3}$ & $6.7(4.9-12.7)$ & $6.7(5.3-15.2)$ & $6.0(2.5-15.5)$ & $5.7(4.6-12.0)$ & $6.0(3.5-14.1)$ & 0.994 \\
\hline $5.0-10.0, \times 10^{3}$ & $3.2(2.5-5.3)$ & $3.5(2.1-7.1)$ & $3.2(1.4-7.4)$ & $3.9(1.8-4.6)$ & $3.5(2.5-6.4)$ & 0.872 \\
\hline Comfort score & $3.5 \pm 1.2$ & $3.5 \pm 1.5$ & $3.8 \pm 1.3$ & $3.5 \pm 1.2$ & $3.3 \pm 1.3$ & 0.593 \\
\hline
\end{tabular}

FIGURE 1 Aerosol particle concentrations at baseline and during the use of different devices for patients with tracheostomy. The concentrations for aerosol particles at each size are presented as median (interquartile range), comfort score is presented as mean \pm SD. HMEF: heat-moisture exchange filter; LVN: large volume nebuliser. ". compared among five devices (Friedman test).

with the patient, and activities (talking or moving around) were discouraged. The door of the patient's room remained closed and none of the rooms had negative pressure. If suctioning was required, aerosol particle concentration measurement was paused and restarted $10 \mathrm{~min}$ after suctioning. Patient's comfort was self-evaluated using a visual numerical scale ranging between 1 (very uncomfortable) and 5 (very comfortable) [12].

HMEF was expected to reduce the aerosol particle concentrations, with treatment effect set at medium to large as 0.1. Using G-power software to calculate the sample size in repeated ANOVA measures, with confidence level $(\alpha)$ of $95 \%$, power $(1-\beta)$ of $80 \%$, the number of patients was 12 . Friedman test was used to compare the aerosol particle concentrations and comfort scores among five devices (including baseline with HMEF) and Wilcoxon signed-rank test was used to analyse the differences between devices. A p-value $<0.05$ was statistically significant for all tests. Data analysis was conducted with SPSS software (SPSS 26.0; IBM Corp., Armonk, NY, USA).

12 patients were enrolled, with mean \pm SD age of $50.5 \pm 16.6$ years, height of $166.5 \pm 10.4 \mathrm{~cm}$, weight of $83.1 \pm 27.6 \mathrm{~kg}$, and body mass index of $29.5 \pm 7.6 \mathrm{~kg} \cdot \mathrm{m}^{-2}$. Tracheostomy had been in place for 18.5 (5.3-250.5) days, 10 patients had tracheostomy tube size of 6, of whom four had cuffed tubes, while two patients had tracheostomy tube size of 4 . All cuffs were deflated during the study. Patients required suctioning with a frequency of $3(2-5)$ times in the past $24 \mathrm{~h}$. Only two patients required suctioning during the duration of the study, which lasted $\sim 90$ min per patient.

No significant differences in aerosol particle concentrations at each size were found among the different devices (figure 1). Patients' comfort was similar among the devices as well.

Aerosol particle concentrations were similar among different humidification devices used with tracheostomy patients with a deflated cuff. These findings differ from our previous study of high-flow nasal cannula for COVID-19 patients, in which aerosol particle concentrations at 1 foot from patients were reduced when placing a surgical mask over nasal cannula at particle sizes of $0.3-5.0 \mu \mathrm{m}$ [5]. In contrast, the effect of placing a bacterial/viral filter or HMEF on the tracheostomy tube was negligible. Hypothetically, a bacterial/viral filter or HMEF should have higher efficiency to filter aerosol particles than a surgical mask. However, all of the tracheostomy patients could breathe via their mouth and nose, and 
none wore a surgical mask. In contrast to COVID-19 patients in the acute phase, the stable tracheostomy patients enrolled in our study required minimal suctioning and barely coughed during the study, while cough in patients without tracheostomy was found to generate higher fugitive aerosol particle concentrations than nebulisation [13]. Future studies should explore whether placing a surgical mask to cover the mouth and nose for tracheostomy patients with a deflated cuff could reduce the aerosol particle concentrations, and to investigate the effects of a bacterial/viral filter or HMEF with a surgical mask during cough or suctioning.

Interestingly, LVN with tracheostomy mask did not generate higher aerosol particles than the other devices, in contrast to a small volume nebuliser, which was found to significantly increase the aerosol particle concentrations [14]. This difference might be explained by the long tubing (3 m) used to connect the LVN and tracheostomy mask and the aerosol output produced with more particles deposited in the tubing, allowing mostly small particles of $0.3-0.5 \mu \mathrm{m}$ to reach the patients.

There are several limitations. Due to the unknown transmission risk of tracheostomy, we did not enrol COVID-19 patients; however, COVID-19 patients recovered from the acute phase and weaned off the ventilator would be expected to have low virus load [15], and less frequent cough, thus our results might provide a reference for future studies with tracheostomy patients with airborne disease. We did not investigate the virus load, while the aerosol concentrations only indirectly reflected the transmission risk, future studies are needed to measure the virus load with different devices. Regardless, appropriate PPE is still recommended when taking care of tracheostomy patients, especially during suctioning.

For stable tracheostomy patients with uncuffed airways, different humidification devices and interfaces did not generate clinically significant differences in aerosol particle concentrations. Future studies are still needed to assess the effects of humidification devices during coughing or suctioning, and the effects of wearing a surgical mask.

Jie Li $\oplus^{1}$, Carla Schoenrock $\oplus^{1}$ and James B. Fink ${ }^{1,2}$

${ }^{1}$ Dept of Cardiopulmonary Sciences, Division of Respiratory Care, Rush University Medical Center, Chicago, IL, USA. ${ }^{2}$ Aerogen Pharma Corp., San Mateo, CA, USA.

Corresponding author: Jie Li (Jie_Li@rush.edu)

Acknowledgement: We thank all the patients who participated in this study. We also thank Amnah Alolaiwat and Lauren J. Harnois from Rush University Medical Center for their help in recruiting patients and implementing the study. We also appreciate Sharon Foley from Rush University for her consultancy in statistical analysis.

Provenance: Submitted article, peer reviewed.

This study is registered at www.clinicaltrials.gov with identifier number NCT04654754. Deidentified data will be available upon reasonable request after publication.

This study was approved by the institutional review board in Rush University Medical Center (approval number 20112506-IRB01).

Author contributions: J. Li and J.B. Fink conceived the idea for this study. C. Schoenrock and J. Li implemented the study. J. Li performed data analysis and drafted the manuscript. J. Li, C. Shoenrock and J.B. Fink interpreted the data. All authors reviewed and approved the final version.

Conflict of interest: J. Li received research funding from Fisher \& Paykel Healthcare Ltd, Aerogen Ltd, and the Rice Foundation; and lecture honoraria from the American Association for Respiratory Care, Aerogen Ltd and Fisher \& Paykel Healthcare Ltd. J.B. Fink is Chief Science Officer for Aerogen Pharma Corp. C. Shoenrock has no conflicts to disclose.

Support statement: This study was supported by unrestricted research funding from Fisher \& Paykel. The company had no role in the study design, data collection, analysis, preparation of the manuscript or the decision to publish the findings. Funding information for this article has been deposited with the Crossref Funder Registry. 
References

1 Liu Y, Ning Z, Chen Y, et al. Aerodynamic characteristics and RNA concentration of SARS-CoV-2 aerosol in Wuhan hospitals during COVID-19 outbreak. Nature 2020; 582, 557-560.

2 Dhand $\mathrm{R}$, Li J. Coughs and sneezes: their role in transmission of respiratory viral infections, including SARS-CoV-2. Am J Respir Crit Care Med 2020; 202: 651-659.

3 Li J, Fink JB, Ehrmann S. High-flow nasal cannula for COVID-19 patients: low risk of bio-aerosol dispersion. Eur Respir J 2020; 55: 2000892.

4 Li J, Ehrmann S. High flow aerosol dispersing- versus aerosol generating procedures. Am J Respir Crit Care Med 2020; 202: 1069-1071.

5 Li J, Fink JB, Elshafei AA, et al. Placing a mask on COVID-19 patients during high-flow nasal cannula therapy reduces aerosol particle dispersion. ERJ Open Res 2021; 7: 00519-2020.

6 Rovira A, Dawson D, Walker A, et al. Tracheostomy care and decannulation during the COVID-19 pandemic. A multidisciplinary clinical practice guideline. Eur Arch Otorhinolaryngol 2020; 278: 313-321.

7 McGrath BA, Brenner MJ, Warrillow SJ, et al. Tracheostomy in the COVID-19 era: global and multidisciplinary guidance. Lancet Respir Med 2020; 8: 717-725.

8 Kaur R, Weiss T, Perez A, et al. Practical strategies to reduce nosocomial transmission to healthcare professionals providing respiratory care to patients with COVID-19. Crit Care 2020; 24: 571.

9 Hernández Martínez G, Rodriguez ML, Vaquero MC, et al. High-flow oxygen with capping or suctioning for tracheostomy decannulation. N Engl J Med 2020; 383: 1009-1017.

10 Lersritwimanmaen P, Rittayamai N, Tscheikuna J, et al. High-flow oxygen therapy in tracheostomized subjects with prolonged mechanical ventilation: a randomized crossover physiologic study. Respir Care 2021; 66: 806-813.

11 Birk R, Händel A, Wenzel A, et al. Heated air humidification versus cold air nebulization in newly tracheostomized patients. Head Neck 2017; 39: 2481-2487.

12 Mauri T, Galazzi A, Binda F, et al. Impact of flow and temperature on patient comfort during respiratory support by high-flow nasal cannula. Crit Care 2018; 22: 120.

13 Bem RA, van Mourik N, Klein-Blommert R, et al. Risk of aerosol formation during high-flow nasal cannula treatment in critically ill subjects. Respir Care 2021; 66: 891-896.

14 O'Neil CA, Li J, Leavey A, et al. Characterization of aerosols generated during patient care activities. Clin Infect Dis 2017; 65: 1335-1341.

15 Lescure FX, Bouadma L, Nguyen D, et al. Clinical and virological data of the first cases of COVID-19 in Europe: a case series. Lancet Infect Dis 2020; 20: 697-706. 